\title{
Plagues in Classical Literature
}

\author{
by Rachel Finnegan \\ Waterford Institute of Technology
}

In an attempt to analyse man's condition, writers have traditionally drawn on sickness and devastation - epitomised in the often abstract theme of plague.[1] That man throughout history has displayed a morbid fascination for both disorders of the human body and great disasters, natural or man-made, is evident from the extent to which he has dwelt on such themes in literature and has maintained this interest through the modern media of cinema and television. These preoccupations, which appear in the Classical world and continue through the Bible, Shakespeare and more modern forms of literature, explore man's dilemma in the face of flood, earthquake, fire, drought, hurricane and pestilence. Similarly, the story of man's fight against disease has been chronicled through the ages, reaching an unequalled popularity in this century with film dramatisations of 'doctor' books and with a succession of TV soap operas which though permitting apparently unending opportunities for variety of character and incident - nevertheless display the same fundamental theme of medicine and science combating sickness and death.

It is the aim of this study is to examine the role and function of descriptions of plagues (loimos in Greek and pestis in Latin) in the works of five major classical writers. An attempt will be made to determine the possible influences, impacts and motives of each author in presenting his particular theme of plague.

\section{LOIMOS - Thucydides}

In book 2 of his Histories, a monumental prose account of the Peloponnesian War, the historian Thucydides presents a powerful analysis of the great Athenian plague. This occupies eight chapters - reflecting, no doubt, the monstrous damage, both physical and psychological, the author believed to have been inflicted on both the Athenians and on society as a whole. As the author is at pains to point out, he is well equipped to deal with such a subject since he was a victim of the plague himself.

Thucydides stresses the enormous amount of destruction caused by the plague and the inability of the physicians to check its course; and notes with regret the victims' gradual resignation to their fate. After suggesting Ethiopia as the plague's probable source of origin, and having described its arrival at Athens, Thucydides sets out to chronicle its actual course and to explain the symptoms suffered by its victims. The description of the actual symptoms reveals his minute powers of observation and unusual literary skill, so that the reader experiences both the physical and emotional sufferings of the victims. There are, for example, harrowing accounts of men, tortured by thirst, throwing themselves into cisterns for relief.

Thucydides moves from symptoms to other aspects of the plague, in particular the disastrous effects which it wrought upon society as a whole. In the strict antithetical style characteristic of this historian, the difficulties of trying to control and contain the disease are represented. No matter how much care was applied, the resulting death of both patient and nurse was almost inevitable. In observing this fact, the historian has been attributed with the responsibility in modern medicine of the process of contagion. This challenged the traditional and widely held belief that plague and pestilence resulted from divine or supernatural agencies.

Regrettably, such a revolutionary theory had no influence on Thucydides' contemporaries. It was almost ignored until W.G. Fracestoro published De Contagione in 1536, and not until the nineteenth century were the causes and consequences of contagion accepted by the medical profession. Thucydides has also been credited with the original concept of the phenomenon of acquired immunity, and it is believed that if the Hippocratic writers had taken more notice of him, the subsequent history of medicine would have been completely different.

In the same way, the historian's great power of perception is clearly indicated in his recognition of the dangers of overcrowding - an awareness obviously not shared by the generals in charge of the war. He tells, with grim realism, of the squalor inflicted upon the Athenians by the influxes of people fleeing from the countryside. As a result of the sudden expansion of populations in the Mediterranean at around this time, concentrated areas of fairly recent massive urban growth such as Athens were extremely vulnerable to any outbreaks of unfamiliar infectious disease. Thucydides' plague devastated and demoralised the population, dealing the empire a blow from which it never fully recovered, and which probably altered the whole course of the political history of the area. The fate of the dying, the dead and the disposal of bodies is portrayed with exceptional vividness, with the description of bodies of the dying being heaped one on top of the other, and with half-dead creatures staggering about in the streets or flocking around the fountains in their desire for water.

His reference to acts of shamelessness encountered in the burial of such unfortunate victims enables Thucydides to make a moralising transition to the theme of lawlessness, and he discusses anti-social and criminal behaviour, either newly indulged in or practised more openly in this time of upheaval and despair. Sins such as avarice, selfishness and lust were provoked by the knowledge that this disease did not discriminate between the good and the evil, and that life had better 
be lived to the full.

It has often been suggested that a historian cannot re-create the past unless he is willing to re-live the experiences of those he is discussing. Plutarch, for example (in his Moralia, 347 A), commends Thucydides on exactly this trait; the latter's stunning description of the Athenian plague and the desperation of its victims demonstrates his ability in this respect, and surely establishes him as a truly great historian. Other critics note the strong Hippocratic influence on the historian's style - in particular, the theory of prognosis, which holds that a medical practitioner will better be able to effect a cure if he can foretell, from the present symptoms, the future of the course of the disease. In accordance with this procedure, Thucydides outlines the various symptoms of the unfortunate victims. In doing so, he uses the standard medical terminology of the time, and does so with such great precision that his description has enabled many scholars to try to establish the actual nature of the disease. Among the various contenders are measles, typhus, and even syphilis. Other writers, however, question the validity of even attempting to identify a disease separated from us by more than 25 centuries and whose symptoms cam be expected to have undergone enormous evolutionary change.

\section{Sophocles}

The wealth of medical terminology and imagery in Greek tragedy has recently been well documented by critics, most of whom recognise a strong Hippocratic influence. It would appear that the tragedians of the fifth century BC resorted to medical science as an important contemporary source of language and ideas, since their own inherited language was inadequate to express the new concepts and ideas of this intellectually flowering period.

We can see important examples of the tragedians' preoccupation with the idea of sickness and healing - especially of the mind - in characters such as Orestes (The Oresteian Trilogy), Pentheus and Agave (Bacchae) and Medea, as portrayed by Euripides. In such plays, characters showing any abnormal or excessive display of emotions - love, anger, ecstasy, jealousy or revenge - are often portrayed and described as diseased or deranged. Their symptoms include spinning eyeballs, amnesia, foaming at the mouth and acute depression, with madness frequently manifesting itself in their erratic speech.

When a character from Greek tragedy is afflicted in such a way, it is normally the result of divine punishment for an impious word or deed, whether done consciously or as the fulfilment of a curse or prophecy. The patient or victim of this sickness, since he or she is regarded as polluted, cannot be cured by a physician, but must undergo purification of a religious nature. Thus, two important strands of Greek culture are combined - a religious theme cast in medical terminology. Whole dynasties such as the House of Pelops can be systematically destroyed as the result of acts of impiety, but the idea is extended further when an actual city, along with its entire population is seen to be suffering from a nosos, or has been struck by plague.

Just as in the case of an individual, the diseased city, in order to be rid of the plague, must be purified by the permanent removal of the infectious source. In the case of Sophocles' Theban plague - the subject of this section - the guilty party turns out to be King Oedipus himself. This plague, whose meaning and significance is discussed below, is represented by Sophocles as an addition to the customary three-fold curse (blighted crops, dying cattle and barren women) associated with divine wrath.

One factor which, no doubt, contributed to Sophocles' apparent interest in medical matters, is his alleged connection with the cult of Asclepius, the great healing god. Our knowledge of this aspect of his life is, sadly, limited, but it is generally accepted that one of the consequences of the plague was the introduction of the cult of Asclepius into Athens in the year $420 \mathrm{BC}$. Sophocles was given official duties in its establishment, and is said to have composed a paean, or hymn, in honour of this god. According to the Vita or Life, Sophocles, was, in return, posthumously honoured as the hero Dexion. He was also a priest of Halon, a minor deity, who is recognised as having studied with Asclepius under Chiron. It is hardly surprising, then, that Sophocles presents Oedipus first and foremost as a physician, who can cure Thebes of this dreadful disease; and that this image is one of the most fully developed in the play. This idea has been discussed by several critics, some of whom have made detailed analyses of the various technical medical terms (normally found only in medical texts) appearing throughout the play.

It is the matter of chronology which poses the most serious problem, and although some critics succeed quite convincingly in proving that the Theban plague does, in fact, mirror the true Athenian epidemic, others are, on the whole, unwilling or unable to commit themselves fully to the idea of a definite Thucydidean influence.

The meaning of the plague within the context of the play seems quite clear. It is a symbol of Oedipus' sin - a miasma which is polluting the whole land, attacking all forms of life and reproduction. This plague is the climax of the seventeen years of guilt allowed to build up since the curse was first fulfilled. As with any sickness, the cause - in true Hippocratic tradition - must be identified and a remedy sought and applied. A cure which in this case involves purification in the form of exile or death. Ironically, it is the very man chosen by the people as physician, and regarded as their trusted ruler and priest-figure, who is the source of infection. It is his gradual realisation of this facet that occupies the greater part of this drama, the plague itself merely acting as a dramatic and ominous starting-point.

Unlike Thucydides, who recognised the natural causes of the Athenian plague and dismissed all superstitions surrounding it, Sophocles reverted to the more religious approach of the poets, particularly Homer and Hesiod. The supplicants, clutching olive-boughs, with a priest of Zeus as spokesman, beseech their king to find a remedy for the sick 
town. His only hope is through consulting Apollo at Delphi, whose reply is duly interpreted by the blind seer Teiresias. This strong dependence on, and trust in, such gods in such a catastrophic time, has been interpreted as Sophocles' recognition of the irreligion produced by the Athenian plague, and his attempt to draw a different lesson from the Theban pestilence. In other words, to show to his audience the importance of prayer, faith and piety, in times of need. Oedipus' guilt, of course, is allegorical, and can be viewed as the collective guilt of mankind.

The Theban plague has been recognised as the most important historical allusion in this drama - a fact which is helpful in trying to determine an exact date - some time between January 424 and the summer of 426 BC. It is possible that the various symptoms of the traditional, Theban, blight would also have existed in the Athenian plague - the lack of crops reflecting the annual devastation of the fields by the marauding Peloponnesian armies; the blight on the cattle representing the live-stock shipped off to the neighbouring island of Euboea or dying of neglect; and abortive births, being a typical symptom in many plagues, such as the one in Thasos, recorded inThe Epidemics.

We can see from Thucydides' memorable descriptions of funeral pyres, symptoms of internal burning, and burning thirst, that fire was a very important element in plagues themselves and consequently in accounts of them. Fire is also, of course, very much associated with various religious and medical practices. Neither Samuel Pepys nor Daniel Defoe, of course, were unaware of the literary significance of the 'purifying' nature of the great London fire which succeeded the plague of 1665. Fire imagery in this and later plagues was effectively employed by both Harrison Ainsworth (Old St. Pauls) and Thomas Mann (Death in Venice).

Although Thucydides's description of the plague was essentially factual, his purpose was undoubtedly also to demonstrate the futility and horror of war. Sophocles, adopting this theme, ingeniously wove it into the popular mythological story of Oedipus, to produce a highly original and powerful drama. Through the images of plague and war he explores great human issues, relevant not only to Athenian society but to any time and place.

\section{PESTIS - Lucretius}

The aim of this section is to compare the purpose, content and style of thepestis described by Lucretius in Book VI of De Rerum Natura with Thucydides' account, on which it is clearly based. First of all, however, it is necessary to mention the influence of Greek literature on the Romans, and the importance of the concept ofaemulatio, or imitation.

Since the Romans adopted and developed all their literary genres from the Greeks (with the notable exception, perhaps, of satire, whose originality they claimed for themselves), no study of the history of Latin literature would be complete without some acknowledgement of its Greek predecessors. From the end of the third century BC, Hellenism became an abidingly strong factor in Roman civilisation, particularly in literature and philosophy.

Not only were the literary forms borrowed from the Greek tradition, but they also made use of its themes, motifs, metres and styles. Sometimes, Roman writers, particularly poets, simply translated Greek works, although often adding some new and usually Roman dimension. It seems that the concept of plagiarism - the accusation of which was freely made by the Greek authors - had little relevance to early Latin literature. The concept ofaemulatio, far from being a disgrace, was highly acceptable and widely practised in the Roman world. Given this Roman tendency to imitate, it is not surprising that Lucretius' description of the Athenian plague was later to be expanded upon by other Roman poets - each work, however, becoming further removed from the Greek original.

The fact that Lucretius concluded his great epic De Rerum Natura (or On the Nature of the Universe) ends on such a morbid note - with his moving description of plague and death - has been a constant source of debate for modern critics. While some believe that the poet was cut short at Book VI, obviously intending to continue, others are convinced that this was contrived as a symbolic and dramatic ending.

At line 1090 of Book VI, Lucretius announces his intention to explain the causes of disease, which he attributes to the gathering together of noxious particles - motes of sickness and death. His image of plague as a hostile, snake-like sky descending upon the water, grain-fields and other forms of nourishment, provides a powerful and vivid introduction to his account of the Athenian plague.

The general outline of this is as follow: the plague, beginning in Egypt, spread to Athens, where it attacked and killed multitudes of the citizens. Acute anxiety was added to the pain caused by the downward-spreading disease, whose symptoms - particularly that of intense burning - were both external and internal. The physicians found it impossible to deal with the situation. Lines 1182-1207 contain a detailed and horrific picture of the 'obvious signs of death', and this is followed by an account of the effects of the plague on animals and birds. The hopelessness of the victims is then described, as are the psychological implications of such widespread and inevitable death. All perished - the cowards refusing to help the needy, together with the brave and generous of spirit. The former, however, were to suffer the indignity and shame of dying alone and unmourned. Notable features of the plague were the desperation of those trying to bury their dead, the widespread grief and the fact that no-one escaped.

Similar scenes occurred in the countryside, and those fleeing to the towns increased the spread of infection and added to the congestion and chaos. After a horrifying description of the streets lined with dead and dying victims, Lucretius discusses the effects of the plague on religion, condemning the practice of filling the temples with corpses and deploring the fact that the people were reduced to fighting over the disposal of their dead. 
From this summary, it is evident that Lucretius relied heavily on Thucydides, both from a structural and a thematic point of view. Lucretius' adaptations and developments, however, are of more interest than the similarities in the texts. Apart from the differences between the two languages, the most obvious and important factor is the medium he employed - the epic poem. Whereas Thucydides had the freedom of prose, Lucretius chose to expound his ideas in the more restricted frame-work of the hexameter. Furthermore, one is an historical account of a plague, recorded for a didactic purpose, while the other is a piece of highly imaginative poetry.

Lucretius' poetic originality can be seen from the following examples: the use of traditional poetic proper names such as Cecrops and Pandion; the image of the tongue as the mind's interpreter; an elaboration on the theme of intense thirst, which is described as 'drowning' the victims; a dramatic picture of the signs of death, extending for 40 lines, including a reference to victims amputating their own genitals in an attempt to evade death; a fuller treatment of the theme of animals and the special attention paid to the emotions of the victims, their friends and relatives.

Having given his account of the causes of birth, growth and life, Lucretius, as an illustration of destruction, sickness and death, chose the most outstanding example of disease ever known in the Classical world - the Athenian epidemic of 430 BC. Since a detailed and well-known account of this catastrophe already existed, Lucretius had only to adapt it and merge it into his own epic. It is ironic that the Lucretian plague - itself a work of pureaemulatio - is perhaps more famous than the original historical account, whose purpose was to aid future generations. This concept ofaemulatio is carried one step further in the following section, which examines the plague described by Virgil inGeorgics III.

\section{Virgil}

Virgil was very much influenced by the publication of Lucretius' work, and proof of this can be found in the many verbal, thematic and stylistic similarities to this work throughout the Georgics. Perhaps the most striking sign of this Lucretian inspiration, however, is the account of a mysterious and devastating plague which, with far reaching consequences, afflicts the animals of Noricum.

Critics are divided on the question of whether or not the Georgics was written for a didactic purpose. It is perhaps fair to say that Virgil's poetry was not primarily intended to teach, but rather to give pleasure; the poet must have been well aware that his work, despite its obvious practical element, would not be read solely for the excellent advice contained in it. Virgil was by no means the first to write an agricultural treatise - he claims that his model was Hesiod, and it is clear that he was also very much influenced by Cato's On Agriculture and Varro's Three Books on Rustic Matters. It is quite possible, too, that Virgil had in mind the Emperor's wish for a return to the old Italian love for agriculture. As well as being an important policy in his social and economic reforms, it was, perhaps, hoped by Augustus, that the revival of such a healthy and noble occupation would improve the moral fibre of Roman society, which had degenerated so much in the previous decades.

In book III, having discussed various aspects of breeding and rearing cattle, horses, sheep, goats and dogs, he then turns to the diseases of sheep and their remedies. This leads him to digress to the subject of a plague at Noricum, thus ending the book on a depressing and morbid note.

Before he reaches the actual description (outlined below), Virgil heightens our impression of the plague's devastation by referring to Noricum's still desolate state, apparent even after such a long lapse of time. The deserted kingdoms are still visible - bringing to mind similar traces of past devastation still to be found in our own time. The overgrown remains of English Doomsday villages, abandoned since the Black Death, and ruins of settlements in Ireland, deserted since the Great Famine.

Virgil relates how the plague (which he likens to a furnace) stemmed from polluted air which affected the livestock through food and water supplies. Early symptoms included a burning fever which coursed through the veins and contracted the limbs, followed by a sort of dropsy. Consequently, sacrificial victims died on the altars; their blood was insufficient for the rites and their entrails were so badly corrupted that the bewildered priests could not take the auspices. A gory description of symptoms in the advanced stages of the disease includes intense burning, leading to severe nosebleeding and dryness of the mouth. The traditional remedy of pouring Lenean wine down the animals' throats irritated their malady still further, causing them to bite and mutilate themselves.

The account becomes increasingly descriptive, with a lengthy, rhetorical and moralising digression about the undeserved death of an ox. Now man must perform the tasks of ploughing and sowing himself. Wolves no longer prowl and fish are washed up dead on the shore. Snakes perish, and birds drop out of the sky. Change of pasture and medicines are useless and the ghastly Tisiphone relentlessly drives before her Disease and Death. While animal cries of terror and pain are heard throughout the land, the Fury adds to the rotting piles of carcasses in stable and stall. The hides and fleeces of the victims are disease-ridden and Virgil warns that the infection will spread to humans if they don their skins.

Whereas Thucydides and Lucretius try to give a rational explanation for the cause of the Athenian plague of $430 \mathrm{BC}$, Virgil sets the plague of Noricum (somewhere between the Danube and the Alps) in some distant, unknown past, and attributes the cause to the weather. If we add to this the fact that we are dealing with a fictitious animal epidemic, it is clear that Virgil's plague description, although modelled on that of Lucretius, is essentially different, much of the material being purely rhetorical and metaphorical. It seems to have gone one stage further in the imaginative development of the plagues discussed so far. 
Many of the symptoms described in the Virgilian plague are unlikely, in comparison with the quite credible examples in Lucretius, and are clearly used to provide rhetorical and emotional effects. The description of an unsuccessful sacrifice indicates that religious worship is brought to a standstill, and this severance of the link between man and the gods is a further instance of man's inability to control his own destiny.

Virgil attributes to animals human emotions. Gentle dogs turn mad and the noble athletic horse sinks into miserable apathy. Virgil's concentration on the psychological aspects of the disease is clearly an imitation of the Thucydidean original which was later employed by Lucretius.

On the question of medicine, Thucydides merely stated that the physicians were unable to cope. In the Theban plague, the metaphorical remedy is attained by the permanent removal (death or exile) of the source of the disease - Oedipus; yet in Lucretius, little attention is paid to a cure, to enable the poet to get on with his examination of man's psychic degeneration. We do find in Virgil, however, the mention of an attempted remedy, but this seems to be yet another excuse for a gruesome story - the cure, ironically, turning out to be fatal to the victim.

The ominous figure of the Fury, 'Vengeance', re-introduces a religious and superstitious element, reverting to the preThucydidean idea of plague inflicted on man (or animals) by wrathful gods. Also present is the recurring theme of burying the dead and the terrible consequences if man fails to perform this sacred duty. The emphasis given to this topic indicates that the problem was a serious one, intensified by war.

In discussing animal husbandry Virgil, naturally, dealt with disease and cure. From this stemmed his novel idea of a cattle plague, in imitation of Thucydides and Lucretius. Although it is an imaginary situation, dealing with animals rather than people, and set in the indefinite past, it is nevertheless a serious aspect of the Georgics, exploring basic moral issues such as religion, justice, duty and trust. An obvious modern parallel to the work is, of course, George Orwell's book, Animal Farm.

\section{Ovid}

The account of the plague in Book VII of the Metamorphoses (516-621), although undoubtedly modelled on those of Lucretius and Virgil, is nevertheless typical of Ovid's unique and inventive style. By selecting and elaborating on certain of their ideas and omitting others, he has made his pestilence perhaps the most original, and definitely the most lighthearted of those in this study.

By the first century BC it would appear that the plague had become a stock theme in poetry, and Ovid, drawing on his knowledge of mythology, used his literary talents to describe a pestilence in the Metamorphoses. Accounting for the absence of familiar faces, King Acaeus describes to a visiting ambassador a terrible epidemic which has recently devastated his island. His pretence to not being able to describe such a ghastly event is purely a rhetorical, literary convention - he has every intention of describing thepestis, and does so in a dramatic, poetic way.

In the poem, Juno was so outraged that the island of Aegina had been named after one of her husband's illicit lovers, that she inflicted a devastating plague on its inhabitants. The theme of Juno's jealousy and revenge is, of course, traditional in Classical literature, especially in Latin love elegy. Ovid blends the old idea of plague as divine retribution, with the recurring theme of the impotence of medicine - themes echoed by Boccaccio in his work. Although Ovid imitates and adds to many of the details described in Virgil's account, such as the types of animals affected, he generally plays down the detailed descriptions given by his predecessor. For instance, he mentions dogs, birds, sheep, cattle, boars and hinds only briefly, giving a limited imitation of Virgil's dying bull and rotting sheep.

However, in contrast with Virgil, who includes them among the dead, Ovid describes how snakes flourish - echoing perhaps Lucretius' image of a plague as a hostile sky which crawls snake-like. This not only adds a supernatural element appropriate to the nature and cause of the pestilence, but it heightens the tension and drama. A similar effect is achieved by his notable preoccupation with some of the more gruesome aspects of plague, such as the stench of rotting corpses and rapidly spreading infection. In the poetic language and style normally associated with more pleasing images, Ovid perversely describes the macabre.

While most earlier and subsequent writers have made much of the decadence arising from the various plagues in history, Ovid confines his comments on this matter to an epigrammatic line. Among the more recent examples is Thomas Mann. In Death in Venice (which is steeped in Classical allusions and references) we see, through the eyes of an elderly writer, Gustave von Aschenbach, the sinister progression of Asiatic cholera, which eventually claims him as its victim. The Venetian plague, described as demoralising the 'baser elements in the city' and encouraging 'those anti-social forces which shun the light of day', could be interpreted as a symbolic reflection of Aschenbach's obsession with the young boy Tadzio.

\section{Conclusion}

What began with Thucydides as a moral and practical prose account of aloimos gradually, through the process of aemulatio, evolved into a traditional poetic theme. This has been developed by later writers such as Boccaccio (in Decameron) for dramatic and even humorous purposes, which have moved far from Thucydides' original aim. Take, for example, Monty Python and the Holy Grail - a film purporting to depict life in the Middle Ages. In one scene is a 
grotesque reconstruction of a plague-stricken village. To the cries of 'bring out your dead', corpses are haphazardly dumped on a handcart and frenzied bodies are seen leaping into wells and dungheaps. Following more closely in the Thucydidean tradition, however, is Ingmar Bergman's classic film The Seventh Seal, which attempts, symbolically, to continue the exploration of man's dilemma in the face of the moral, social and physical devastation wrought by plague.

Finally, there are those who regard AIDS as a pestilence sent down from God to punish the human race for its wicked ways. It is only a matter of time before this becomes the subject of a film, novel or poem of truly 'epic' proportions. 